\section{Recordable CD and DVD for Archiving} Q1998 Katherine Cochrane

When CD-ROM was introduced in 1983, it started a revolution in dala storage that is still going on. But it was not until 1992 , when the first desktop CD Recorders were shipped, that the real power of compact disc reached consumers. The ability to make on ones own desktop as few as one disc with up to 650 Megabyte of data in a format that was readable on any computer with a CD-ROM drive, made massive data storage and file interchange a reality. That revolution is continuing with the advent of DVD-Recordable in 1988, allowing up to 3.9 Gigabytes on a single disc. In the next year or so, storing the full 4.7 Gigabytes specified in the DVD standards will be possible.

What does this mean for those of us who have large datasets to archive and distribute? Power, reliability and, thanks, to the standards-driven formals, the assurance that we will not have to constantly migrate to newer media just to be able to read curfiles

These somewhat broad statements are supported by the facts. Lef's start with a discussion of the physical atlibutes of recordable compact disc media, then discuss data format standards.

\section{Physical Characterlstlcs \& Manufacture of CD-Rs \& DVD-Rs}

The materials used in archive-quality recordable compact discs are extremely stable: polycarbonate, gold, polymer dye and acrylic lacquer. If properly stored and handled, good quality discs that are well-reoonded will last for decades, and probably centuries. The catch, of course, is how to be sure that your own discs are good quality and well-recorded. This is not as easy as it should be, but now there is a standard (ANSI IT9.21') that provides guidance for how to test, store, and handle CDs to prevent deterioration of the physical medium to the point of unreadability.

\section{0 \\ WinEDS 3.0 High Performance X-ray Microanalysis For Windows ${ }^{\text {TH }} 95$ / NT 4.0}

This FAST full 32-bit PC Windows ${ }^{T M}$ based analyzer gives you all the performance of more expensive workstation systems.

$x$ Qualitative \& Quantitative software with one click operation.

$\times$ WinEDS PX9000 Pulse Processor DX3000 Eias.

$x$ Interfaces to several delector brands.

× 5 to $10 \mathrm{eV}$ improvement on most detector's resolutions.

* Complete system upgrades - including new detectors.

X Partial upgrades to suit your system needs.

\section{Also}

* Complete line of $\mathrm{PC}$ based imaging systems.

* Top dollar for trade-ins.

X Service for TN5500 and TN2000 systems.

TN Analyzer Service Inc. 7897 Hwy 19

Dane, WI 53529

Tel.: (608)798-2005, Fax: (608)798-1675, eMall: doug_tnas 9 msn.com

Visit our web site: www.tnanalyzerservice.com

Now with demo labs in Florida and Texas, as well as in Wisconsin - and soon on the west coest.
Testing equipment and testing sevices are available from several companies for those who absolutely must know if their data is properly recorded. For others, who cannot afford either the specialized testing equipment or individual testing by a service, redundancy and periodic re-reconding is affordable thanks to the fact that CD-R offers the lowest price per megabye of any recordable medium avallable today. Even with adequale testing facilities and well-recorded discs on good media, though, making several copies and storing them in different locations is the best procedure for critical files. Luckily, CD-R media is inexpensive, so this is not a very costly thing to do.

Just what are the optimal conditions for storing and handling compact discs? Stated simply, a nombl office environment (perhaps a little cooler than some) is ideal: low humidity, moderate, stable temperatures and filtered light. The conditions that damage discs are high humidity, high temperatures over an extended time (especially when combined with high humidity) or rapid temperature changes, and exposure to broad-bandwidh light that could contain wavelengths that would cause the photosensitive dye layer to decompose.

\section{Recordable Compact Disc Composition}

CD-R and DVD-R discs start with an injection-molded, optleal-quality polycarbonate substrate, which has a spiraled track pressed in to it (properly called a wobbled groove) to ensure compalibility amang users. This groove provides a path for the recording laser to follow. On the grooved or data side of the substrate, a polymer dye is applied (it might be either liquid or a film), then the reflective metal (gold or a silver alloy) is sputtered on, and a UV-cured lacquer is spincoated over the metal to protert it from abrasion. A label, printable or protective surface may be applied over the lacquer, but that is optional.

These materials are individually and in combination very stable. Polycarbonate may ouer time absorb moisture and become clouded (heat accelerates this process), but if the humidity and temperature are controlled and moderate, that will take a very long time, up to centuries before the substrate is sufficiently clouded to prewent reading by present-day devices. The polymer dye is also chemically stable, although it must be sensitive to certain wavelengths, since that is how the dala image is recorded. If the dye is protected from exposure to these wawelengths except during the recording process, the dye could also last for centuries sealed within the disc structure. If the metal layer is $24 K$ gold, the noncorrosable properties of this noble metal ensure that corrosion to the point of unreadability will not occur during the lifetime of the other materials. Other metals are sultable for discs used for applications other than archiving, but should probably be avoided for long-term data storage.

Dr. John van Bogart of the National Media Lab wrote me (see hitp://huww. cdinfo.com/CDIC/ndustryinewsiemail-280498.html) that recent tests they have done on CD-ROMs show life expectancies exceeding 100 years, and they are frequently criticized by the industry for being too conservative. Since audio CDs are made with the same materials and using the same procedures (allhough with less error correction coding), they should last nearly as long. More information on these tests might be available at the NML website (htitp:/fwww.rnil.org), but given the problems they have had with misused materials from their site, maybe not. Read the whole story at hitpi/www.codinfo.com/CDIC/Industry/news/mediz problem.html

\section{Hazards to CD \& DVD Media}

The biggest dangers to discs that are well-made and well-recorded are improper storage and handling. Scralches, even very tiny ones, can accumulate and either allow the metal reflective surface to be interrupted, or occlude the polycarbonate substrate to the point of unreadability, and clouded polycarbonate from high temperature and humidity could prevent reading by a laser beam, which must travel through this layer on the way to and from the reflective surface before reaching the laser pickup sensor in the reader. If the metal layer is missing or corroded, or if the substrate is opaque, or if the dye layer deteriorates and becomes opaque to the reading laser's wavelength (in places where it should be clear), this laser beam will not be reflected back to the reader, and the signal will 
not be received by the decoding circuity. The accumulation of enough of these errors (called BLER or Block Enor Rate) will cause the reader's enor detection' efror correction circuits to reject the disc as unreadable. For more information about BLER and other disc testing issues, please see "Is There a CD-R Media Problem" by this author on The CD Information Center website, 2

The disc is recorded by buming it with a laser. According to the compact Disc Handbook by Ken Pohlmann:

The recording mechanism itself may be described as a heat-mode menory. The recording layer is actually a photo-absorbtion surface in that it absorbs energy from the recording laser as heat. Temperature at the focused spot rises above 250 degrees centigrade. This causes the substrate layer to $\mathrm{ex}$ pand into the absorption layer and mix with the dye materials there. Together, the polymer mixed with dye decomposed from heat acts to form pits in the substrate. These pits create the change in reflectivity required by stan dard $\mathrm{CD}$ player pickups: ${ }^{3}$

The readout wavelength and power is difierent from that used to record discs, so there is no danger of a reader inadvertently recording to a disc.

\section{Standards and Data Formats}

The question arises of whether these compact discs can be read $10,25,50$ or 100 years from now. Compact Dise is the first data storage technology to use an industry-wide accepted, open standard, cross-platform data format. If dises are made to meet this standard (or group of standards), they will almost certainly be accessible by future backwards-compatible disc readers. Of course, it is also advisable to use standard file formats that are likely to be supported, as well as following the disc data formats. Operating systems and programs change much more rapidly than disc data standards, which should be kept in mind when making archive discs for long-term storage.

The compact disc industry has recognized the impontance of disc format standards, and at least today is committed to maintaining such backwards compatibility. Like anything else in this world, that could change but right now it looks good. To help maintain that commitment by the industry, concerned users of the technology should become aware of trends in the $\mathrm{CD}$ industry, participate on standards committees, and let the manufacturers know about their desire for backwards compatibility. They do listen. This was made evident when DVD was first proposed to use a format not backwards compatible with CD-ROM or CDRecordable. Users and commentators raised their voices and told the industry this would be an important factor affecting eventual acceptance of the new technology. Now, the MultiRead format has been developed and accepted by $98 \%$ of DVDROM equipment manufacturers, ensuring that most 3rd generation and later readers can access data on CD-ROM, CD-Audio, CD-Recordable and CD-Rewritable discs as well as on DVD media.4

Another development of interest during the transition period from CD-ROM and DVD-ROM is the fact that image files formatted with the DVD-ROM standard can be recorded and used on CD.R and hard disks as well as on the more costly DVD-R media. This means that for data up to $650 \mathrm{MB}$, CD-R media can still be used, and with the backwards compatibility discussed above, will not require migration to DVD-R media just to be usable with DVD-ROM readers, of course, these DVD images can only be read by DVD-ROM drives, but there are good reasons to use the DVD format rather than earlier CD-ROM standards: compatibility across plafforms is much better than under the older formats.

According to Mark Ely, in Publishing in the Age of DVD:

Following the recommendations of the Hollywood advisory committee, the DWD Consortium included specific audio and video formats as well as interactive functions into the DVD 1.0 specification. This is a major advantage that DVD maintains over CD-ROM. In CD-ROM there is no single specification for audio, video, or a file system. This has led many multimedia developers to invent their own audiofvideo formats for delivering interaclive contert. Unfortunately. there is no guarantee that content authored and developed for one configuration of a CD-ROM equipped computer will work with other mod- els. Since DVD has specific audio format, video formats, and a file system, content authored for DVD has the advantage of cross-plafform compatibil$1 \mathrm{ty} \mathrm{s}^{5}$

More information about DVD and DVD-ROM can be found in Jim Taylors DVD $F A Q^{\prime}$ and other web sites. $A$ list of DVD related websites is avaliable from The $\mathrm{CD}$ in formation Center website as well. ${ }^{3}$

\section{Conclusions}

Reliable, long-lived media and industry-wide standards, combined with affordable prices and large storage capacity, make recordable CD-ROM and DVD-ROM excellent choices for long-term, large data set archiving.

Katherine Cochrane is president of The $\mathrm{CD}-$ Info Company, Inc, publisher of information products about the Compact Disc industry, technology and applica. tions, shtpol/www.cd-info.com> She can be reached at katherine@od-info.com

1. American National Standards Institute, shttp:Jwww.ansi orgs

2. Cochrane, Katherine W. Is there a CD-R Media Problem? On the CD Informa tion Center. shttp://www cd-info.com/CDIC/Technology/CD.RMedia/ probiem.htmp

3. Pohlmann, Ken C. 1992. The Compoct Dise Handbook. 2nd ed. A-R Edilions Inc., Madison, WI

4. The Optical Storage Technology Association website chirp:/Wwwosta.orgs

5 Ely, Mark. 19g8. Publishing in the Age of DVD: A Primer for Creating Content for DVD. Ird Ed. Sonic Solutions, chttp:/hww sonic.coms

6. Video Discovery web site at shitp://www.videodiscovery,com/vdyweb/dvdi dudfaq.html>

7. Cochrane, Katherine. DVD Information Page in The CD Information Center, 1958. shtpliww. cd-info.comidvd/s

\section{Take the following microanalysis quiz}

\begin{abstract}
What is the thickness of my film? Does the beam penetrate that particle? What is the best kV to use for this sample? How wide is the beam in my E-SEM? How much does an incorrect analysis cost? How can I improve the quality of my analys is?

\section{Maybe it's time to take a look at the software that can answer these questions}

\section{Electron Flight Simulator}

\section{Analysis Simulation and Modeling Software for Windows}

\section{Small World}

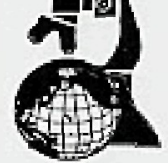

phone/fax: (703) 849-1492

e-mail: dchernoff@aol.com

http://www.small-world net

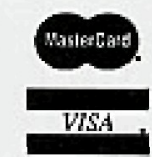




\section{IC and Computer Terminology}

Mary Alexander, Judy Murphy \& Pat Deshaye

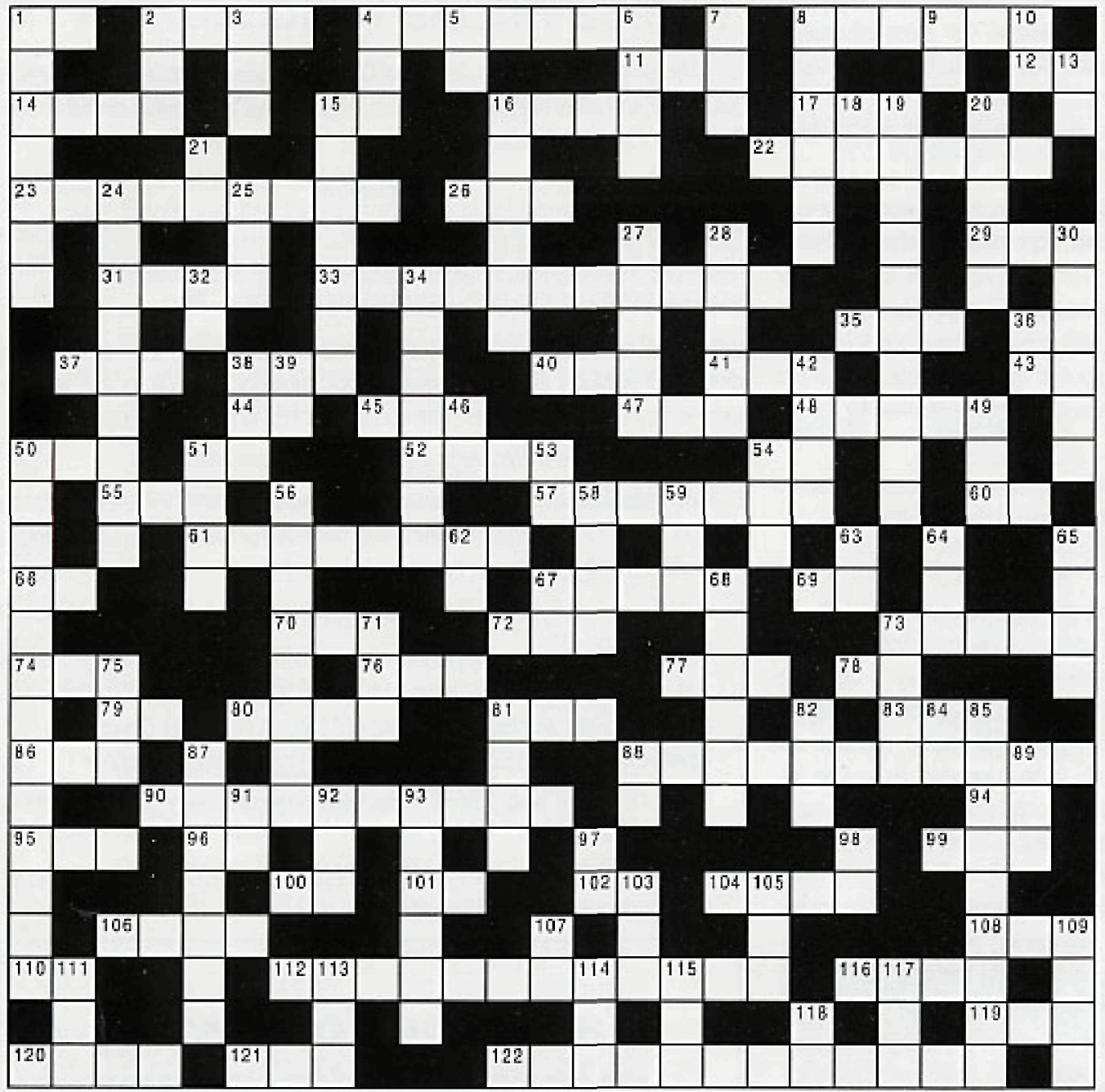

\section{ACROSS}

Reies to 2.98 H foppy disk or extra high densily.

2. Changus eloctron fore in tousisior.

4. Material drifted th EDS dalector crystia to provent cument loss.

8. A machine or tool.

11. Inlord

12. A milim brats, $3 \mathrm{cr}$

14. Complementay metel dxide semicenducor.

15. Wafar material

16. What a Pelior device does

17. Inlemel probool usad by electronic mal pogram to downbed massages from mai servir acr.

22. Micramire.

23. Incresses sianal.

26. Infrated ricrecopy

29. Electrostatio dischame, at

31. Top leyer.

3. Instating laser.

5. Standard unit describing ane volt divided by cre amp-

36. Manipulating images, ac

37. Wire Band site.

38. Organization that adds value to a system and resels it, acr.

40. Interfere behween nebwork, acr.

41. Measuremant unit for resistance.

43. Leecing semioonductor mor. founded in tow at Gophysizal Sevice, Irc, at.

44. Curreal that is rotathernaling, ar.

45. Connotion between lapers of IC pathways.

47. Auminum is a forros motal.

43. Fiold of tonsistars.
50. Smal-scale integratien.

51. A proprietay high-spaed tus used in the VAx series.

52. Hem common to IC's, potatoas and poker.

54. Same as 91 [own.

65. An lBM mainfame prolect that alows tos IES devices to communicate with esch other.

57. Block of pure silion.

60 One billion byles, ar.

b1. Pathej mataria

B6. SEM imaging mode based on phobons, acr.

67. Implant on aurface during dopirs.

69. SEM imaging mode using voltege infoms lon, â

70. Chamical vapor dapccilion, acr. phire, aer.

73. Electronic value

74. A ricrosope using a galium icn source.

76. Type of hardware interface used to connect hard disks to $\mathrm{PC}$, acr.

77. Peckged chip.

78. Firs compary to commetialze the silion transistor, pocket radio, IC, hand-hald cakulator, singlo-chip computer a USP chip ace"

79. Use ol CD-ROM \& vibodise controllad by computer for an interacthe octrity, acr.

80. wire 13 used to conost chics olead trame.

81. Plastic encipalatad devibe, acr.

83. Compular assisted deajon, acr.

B6. Calhcde ray hbe, acr

88. Flaced on water for phobltography.

50. Electronic swibh.

84. Shuty of faulis, Eer.
72. Specifis devibe technelogy utilizing sap-
95. E. Rugka associded with this micosope acr.

56. IVM mainfrarne 4GL that runs under KNS. Originaly designed for norn-compuliti pecple, acr.

99. Vicreccoe stich resolves at alamic level, act:

160. Vaster control program that runs compuler. acr.

101. Eladromagnelic frequencies abore audia and below visible liaht.

102. Ona one-houstath of a will ahome

104. Single hiline memory module, acr.

106. Eloctron beam induced cartent.

108. Scanning acoustis misroscopt.

110. Sodium.

112. Top lajers ol clear insulating malerial on IC chips.

116. Vey lams stá irisalofon, sct.

119. Lutricant

120. Mirosopa for miltilayer inspation.

121. Used as sensor in lad bed ghanners, as.

12. A "peeling awas".

\section{DOWN}

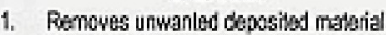

2. Allemative to sit.

3. Organbaton that sets telecommunications slandards wortwide, $0 \%$

4. Intestation bethen 3,00-100,000 transilors on chig, acr.

5. Can-type package for discrele device, acr

8. Very od tem for proceascr inumber curchingl.

Postscript file format, acr.

8. Boron, for example.
9. Inlegrated circuit, ocr.

10. With of one numerite bigit

13. Cammunimations carrier that arobides servises in Great Bitain \& Morthern Ireland, at.

15. Alians waler wilh mask

16. Caramic dual-in-line packego, acr.

18. Technolagy using abjacls, ber

19 N-type dopent.

20. Slibe of Silion.

21. Symbol tor ralio of circumference of circla th its diameter, acr.

24. Prolective cover for chip.

25. Fidd eftot transistor, acr.

27. IC Extrants

28. P-type dapant

30. Applying boron.

32. IBW's first 268-based PC, introduced in 1994.

34. Substrate for elactronic elenents.

5. Formal title for data processing. MIS, or IS dept. Same as Inomation Systems, 20

38. Intsl standerd for speeding up full-malon vistoo porformanca, acr.

39. Common form of alstricity from power plant to hame whose drection is renesed 60 times per sacond in U.S

42. Logic pathem on gless.

46. "- hal' exclaimed the FIB operalor.

4h. Crystal sensar far CCO acr.

50. Detaled deserietien of requiremants.

51. Cross sectonal ves od gale cellod a tbirds :

5. Asidhase measure.

54. Opan atandard based on UNIX and Windows NT to provide users a migraion palh from x6 PCs to MPS AISC machines, no langer usot, ari

50. Eledoric Ement interface

59. Burpon potwey

59. Communication satile thal orbits na higher than 500 miles abore the eath, acr.

62. Cambination of menus, screen design, beyboard oommands, command languege and hep scruers, which creale the way a user interacks with a compuler, acr.

63. Electrical ourent that trats in ond dimation used within computer's ebotronic circuils, acr.

64. Silibon-on-insulator, a device technalogy, acr

65. Si crystal from which ingots are grown.

67. Onist swiches ollon labulat this

68. Polishing device for IC cross saclions

71. Singular of "dice".

73. Die, pural.

75. Valued $a, 0$ or 1

91. Programmable resd-ony manoy.

62. Fälure medanism, as.

64. Arsenic, axi

85. Doping process.

67. Minule cracks in the glassivafion.

8. Compulers that conform to the standard originally develaped by IBM, acr.

60. Mcroscope based on sound.

91. IBU mainframe 4GL that runs under MVS. Originaly designed for nen-xarr puter people.

22. Silicon-on-sapphie, as.

93. Cojse of delanination and ofte falures.

97. 1 times 10 to the eighteanth fower, acr.

qu. Dplical microecoge, acr

103. Computer scroen.

105. A charged abom.

107. Wilinit.

109. lon ; a micromachining devke.

111. Type of scanning probe microscopa, acr.

113. Lit-up display, acr.

114. One of largest commercial on-line servise providers, acr.

115. Slartos ect as Computing-TahulalingFecording 60 , in 1911, acr.

117. Number of linas prirtod in a vertiesl irch, act.

119. Progum to know, explain, and defend results, as.

Reprinted from the Delta Microscopy Newsletter, Volume 12-1, February 1998 